\title{
Mechanical strength of soda-lime glass sandblasted by gravitation
}

\author{
Fouad ROUMILI ${ }^{1}$, Saci BENBAHOUCHE ${ }^{1, *}$, Jean-Christophe SANGLEBOEUF ${ }^{2}$ \\ ${ }^{1}$ Laboratoire de Mécanique de Précision Appliquée, Institut d'Optique et Mécanique de Précision, Université Ferhat Abbas, Sétif, 19000, \\ Algérie \\ ${ }^{2}$ Institut de Physique de Rennes, UMR CNRS 6251 Bât. 10B, Campus de Beaulieu, 35042 Rennes cedex, France \\ Received: 08 October 2014 / Revised: 30 December 2014 / Accepted: 14 February 2015 \\ (C) The author(s) 2015. This article is published with open access at Springerlink.com
}

\begin{abstract}
Damage to a glass surface by sandblasting has a remarkable effect on its mechanical properties and strength. In this study, we analyze the superficial deterioration of soda-lime glass and its influence on the mechanical strength. Sandblasting by gravitation from a fixed height causes damages by the free fall of different quantities of sand, which we performed for a selected grain size and at different angles of inclination. To characterize the surface state, we used different roughness measures (the arithmetic mean value of the roughness $R_{\mathrm{a}}$, the root mean square roughness $R_{\mathrm{q}}$ and the maximum roughness $R_{\max }$ ) and measured the optical transmission (transmittance) at different points on the specimen surface using a profilometer. To determine the mechanical strength, we proceeded by two methods: first, by a shock ball (falling ball), and then by biaxial bending using circular supports. The effects of the surface damage on the optical transmission and the mechanical strength of the glass are graphically presented and discussed in this paper.
\end{abstract}

Keywords: sandblasting; mechanical strength; roughness; soda lime glass

\section{Introduction}

Today, the exhaustion of hydrocarbons as an energy source has oriented the world toward other forms of energy sources that are permanent; thus deserts are considered to be favorable regions for the investment of solar panels. The glass protectors of the panels are subjected to the harsh climatic conditions in these regions that have an obvious effect on their surface states and properties (optical and mechanical), such is the case of all glasses used in deserts (in house windows, car windshields, optical instruments, etc.).

Indeed, it has been demonstrated in Refs. [1-4] that the mechanical strength of glass is influenced by:

- the state of or damage to the surface;

- the length or speed of load;

- the environment.

Damage by sand gravitation is a simple and economical method; it damages a surface state by the free fall of a

* Corresponding author: Saci BENBAHOUCHE.

E-mail: benbahouche_s@yahoo.fr given quantity of sand of known grain size from a fixed height while using a deterioration device [5-7]. Deterioration by sand gravitation is governed by the tendency of a sand grain to create microcracks on the specimen surface.

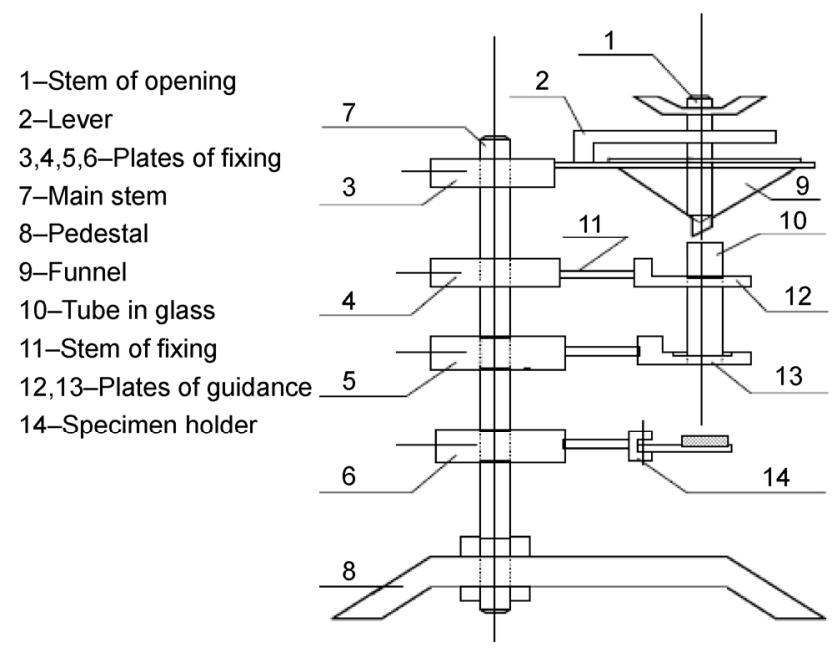

Fig. 1 Diagram of a device used for deterioration of a surface state by gravitation of sand. 


\section{Materials and experimental procedures}

The glass used in this study was a soda-lime-silica float glass manufactured by ENAVA (Entreprise Nationale du Verre et Abrasifs, Algeria). The samples were square shaped and $100 \mathrm{~mm} \times 100 \mathrm{~mm} \times 4 \mathrm{~mm}$ cut from the same plate.

The chemical composition is given in Table 1.

The Young's modulus of $72 \mathrm{GPa}$, Poisson's ratio of 0.22 , and a hardness $6.55 \mathrm{GPa}$ were measured, respectively, by an ultrasonic pulse echo technique and macro indentation. The experimental study was essentially based on the measurement of the roughness by a profilometer (Hommel tester T20DC) for specimens of the soda-lime glass bombarded by different quantities of sand $(100,300$, and $500 \mathrm{~g})$ whose grain sizes were selected by sifting (the diameter measured by the optical microscope "NEOPHOT 21" is: $G=$ $0.456 \pm 0.065 \mathrm{~mm}$ ), for a constant height of sand fall of $1 \mathrm{~m}$, a constant debit $1.66 \mathrm{~g} \cdot \mathrm{s}^{-1}$, and three angles of inclination, $\theta$ of the specimen $\left(\theta=30^{\circ}, \theta=45^{\circ}\right.$, and $\theta=60^{\circ}$ ).

We measured the transmittance at the same point where we determined the roughness, using an MD 100 microdensitometer.

The rupture strength was determined by two kinds of tests:

- The test by the shock ball was performed using a device made in our laboratory, which has the following parameters: step length $L=30 \mathrm{~mm}$ and ball mass $m=24.84 \mathrm{~g}$.

- The test by biaxial bending using two concentric rings was performed on the universal test machine (DY22 5KN) with the following parameters: loading speed $V=5 \mathrm{~mm} \cdot \mathrm{min}^{-1}$, capacity $P=$ 500 daN; precision $\varepsilon= \pm 0.5 \%$ of the measure, radius of the load ring (upper) $r_{0}=10 \mathrm{~mm}$, and radius of the fixed ring (lower) $r=20 \mathrm{~mm}$.

Table 1 Chemical composition of the glass.

\begin{tabular}{cc}
\hline Oxydes & Wt (\%) \\
\hline $\mathrm{SiO}_{2}$ & 72.2 \\
$\mathrm{Na}_{2} \mathrm{O}$ & 15.0 \\
$\mathrm{CaO}$ & 6.7 \\
$\mathrm{MgO}$ & 4.0 \\
$\mathrm{Al}_{2} \mathrm{O}_{3}$ & 1.9 \\
Balance & 0.2 \\
\hline
\end{tabular}

\section{Results}

Before the blasting, we determined the arithmetic mean of the roughness, $R_{a}$, the root mean square roughness, $R_{\mathrm{q}}$, the maximum roughness, $R_{\max }$ the transmittance, $\mathrm{Tr}$, and the mechanical strengths by the shock ball, $\sigma_{\mathrm{rc}}$ and by biaxial bending $\sigma_{\mathrm{rf}}$ using the circular rings, which are summarized in Table 2.

Table 2 Transmittance, mechanical strength, and roughness of the soda-lime glass surface before damage.

\begin{tabular}{cccccc}
\hline $\begin{array}{c}R_{\mathrm{a}} \\
(\mu \mathrm{m})\end{array}$ & $\begin{array}{c}R_{\mathrm{q}} \\
(\mu \mathrm{m})\end{array}$ & $\begin{array}{c}R_{\max } \\
(\mu \mathrm{m})\end{array}$ & $\begin{array}{c}\mathrm{Tr} \\
(\%)\end{array}$ & $\begin{array}{c}\sigma_{\mathrm{rf}} \\
(\mathrm{MPa})\end{array}$ & $\begin{array}{c}\sigma_{\mathrm{rc}} \\
(\mathrm{MPa})\end{array}$ \\
\hline $0.013 \pm$ & $0.014 \pm$ & $0.057 \pm$ & $89.18 \pm$ & $70.39 \pm$ & $95.22 \pm$ \\
0.001 & 0.001 & 0.008 & 1.62 & 12.77 & 6.62 \\
\hline
\end{tabular}

Note: For the mechanical strength measured by the shock ball, the number of shocks repeated is $N_{\mathrm{sr}}=8$.

\subsection{Surface state}

Measurement of the roughness of the surface was done from the superior side of the inclined specimen up to its center, to avoid the effect of rebounding sand on the underside, with steps of $10 \mathrm{~mm}$ along a straight line.

Figures 2, 3, and 4 show the variations of $R_{\mathrm{a}}, R_{\mathrm{q}}$ and $R_{\max }$ with the distance from the point of impact

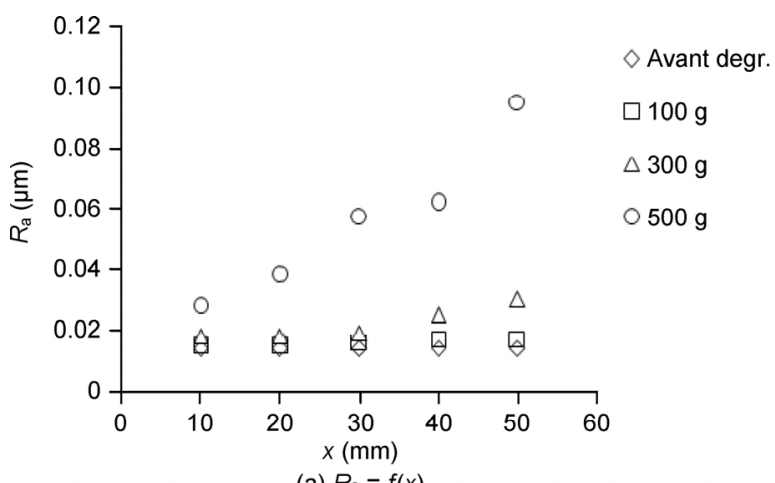

(a) $R_{a}=f(x)$

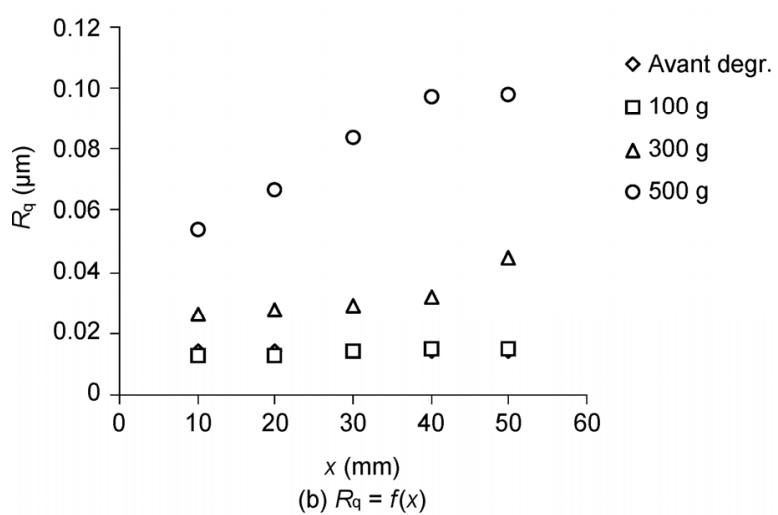

Fig. 2 Roughness variation with the sand impact distance $(x)$ along the surface for $\theta=30^{\circ}$. 

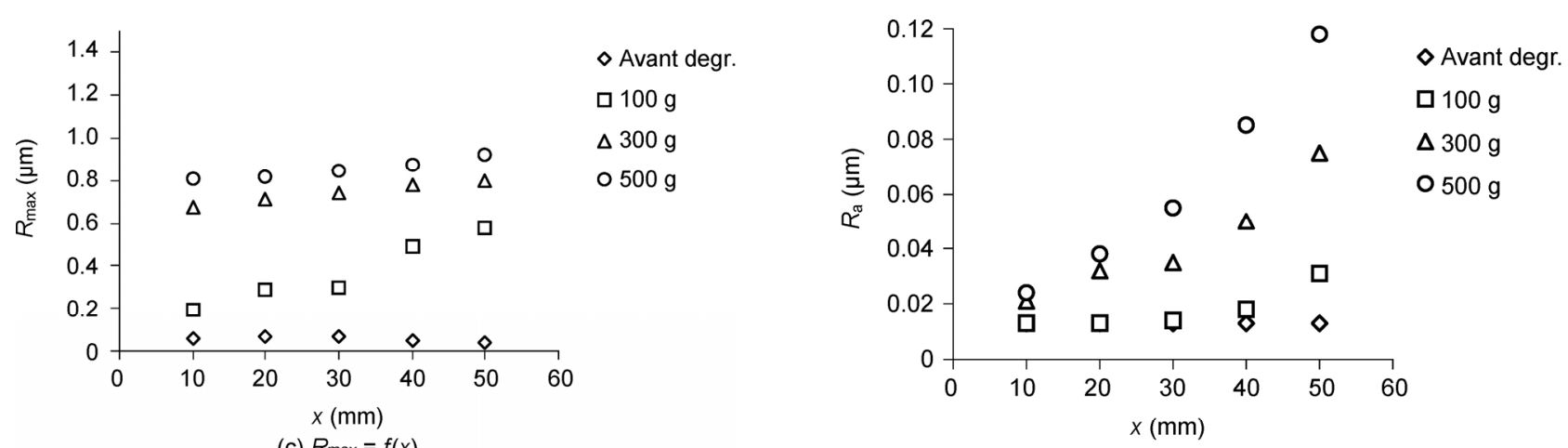

Fig. 2 (Continued)
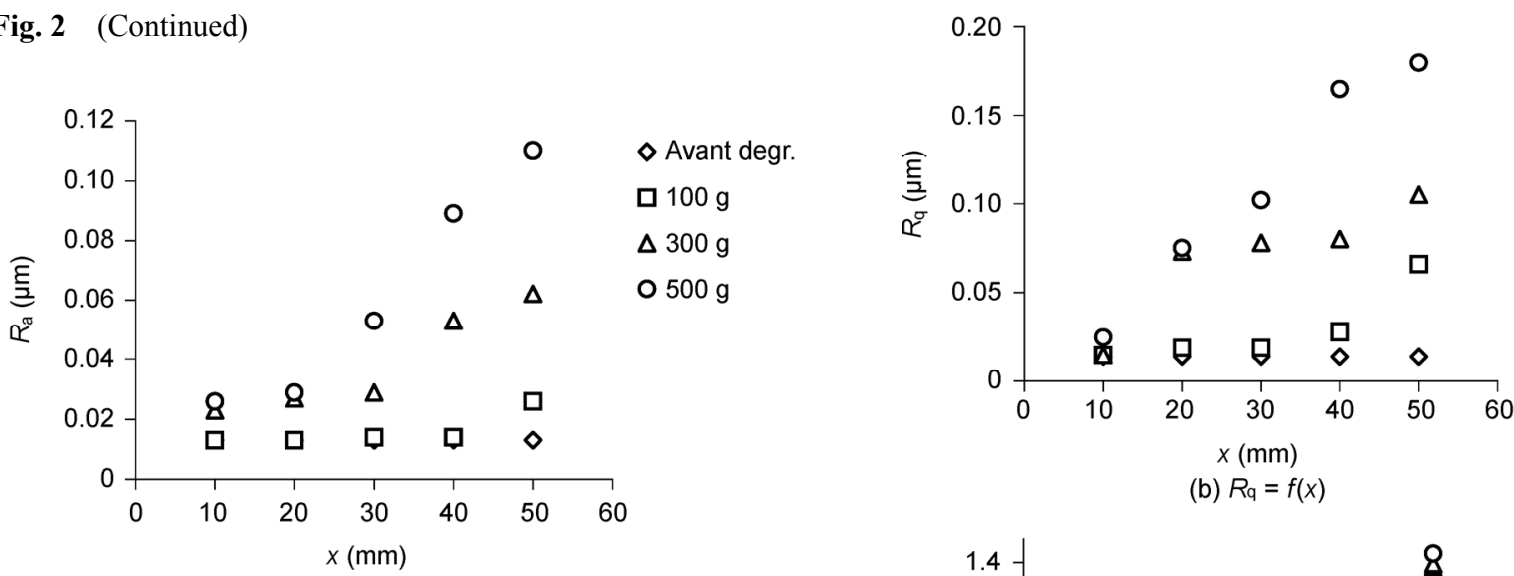

(b) $R_{\mathrm{q}}=f(x)$

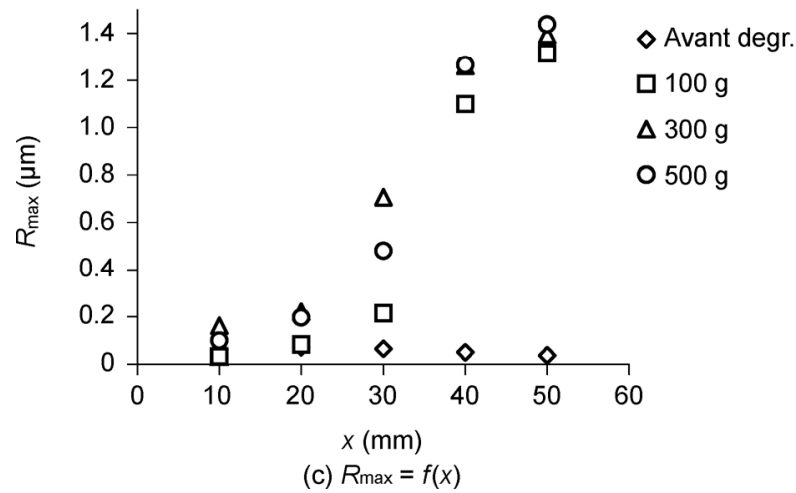

Fig. 4 Roughness variation with the sand impact distance $(x)$ along the surface for $\theta=60^{\circ}$.

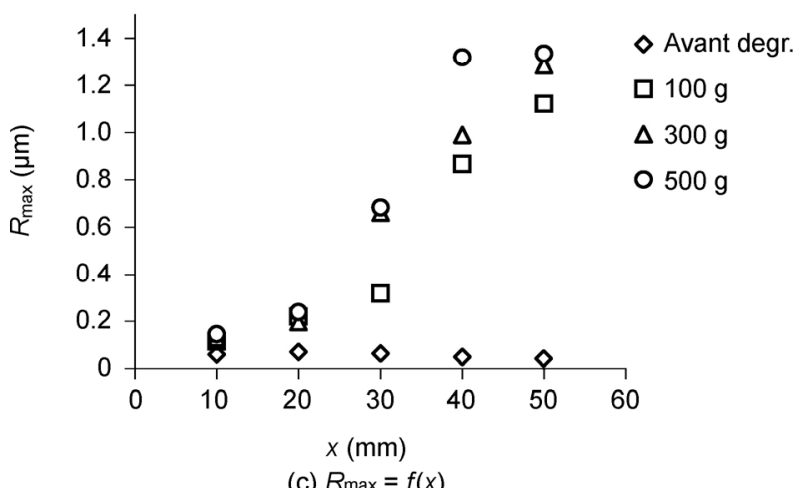

Fig. 3 Roughness variation with the sand impact distance $(x)$ along the surface for $\theta=45^{\circ}$. along the specimen for the undamaged state (Avant degr.); for different quantities of sand $(100 \mathrm{~g}, 300 \mathrm{~g}$, and $500 \mathrm{~g})$ and different angles of inclination $\left(30^{\circ}, 45^{\circ}\right.$, and $60^{\circ}$ ).

\subsection{Optical transmission}

Figures 5, 6, and 7 show the variations of the optical transmission with the distance from the impact point along the sample for the undamaged state (Avant degr.); for different quantities of sand $(100 \mathrm{~g}, 300 \mathrm{~g}$, and $500 \mathrm{~g})$ and different angles of inclination $\left(30^{\circ}, 45^{\circ}\right.$, and $\left.60^{\circ}\right)$. 


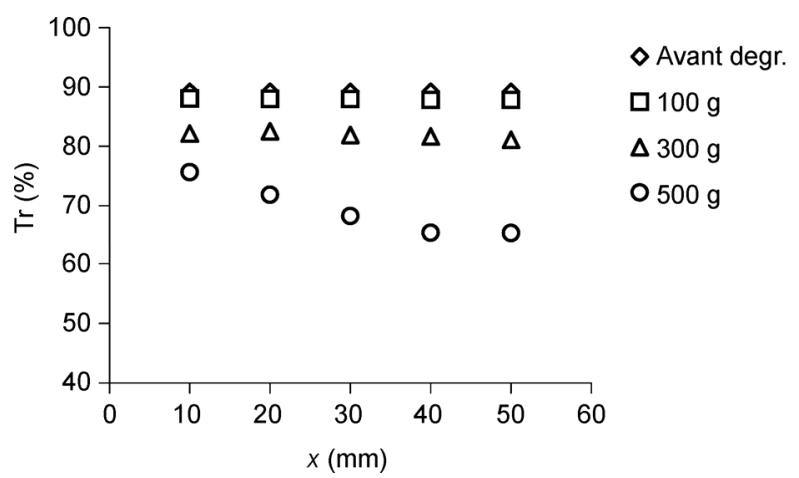

Fig. 5 Optical transmission at distance $\mathrm{x}$ from the point impact of the soda-lime glass damaged by sandblasting for different sand quantities and an angle of inclination $\theta=30^{\circ}$.

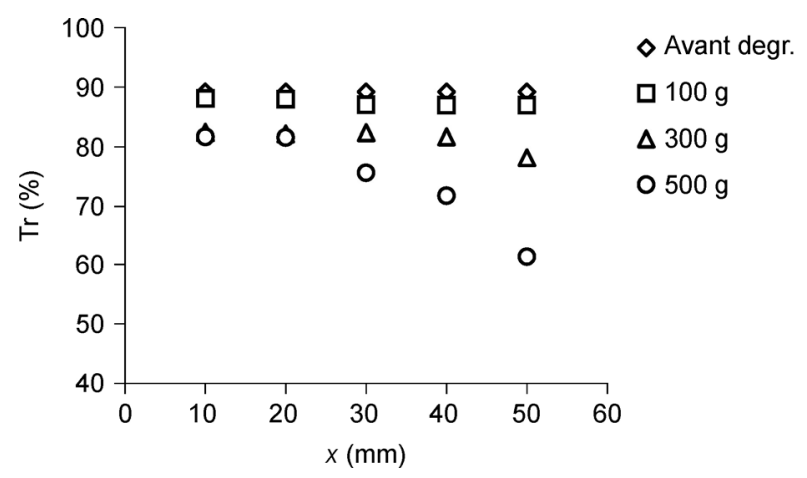

Fig. 6 Optical transmission at distance $x$ from the point impact of the soda-lime glass damaged by sandblasting for different sand quantities an angle of inclination $\theta=45^{\circ}$.

\subsection{Mechanical strength}

\subsubsection{Shock ball measurements}

The results of the mechanical strength measured by the shock ball, $\sigma_{\mathrm{rc}}$ and the corresponding percentage

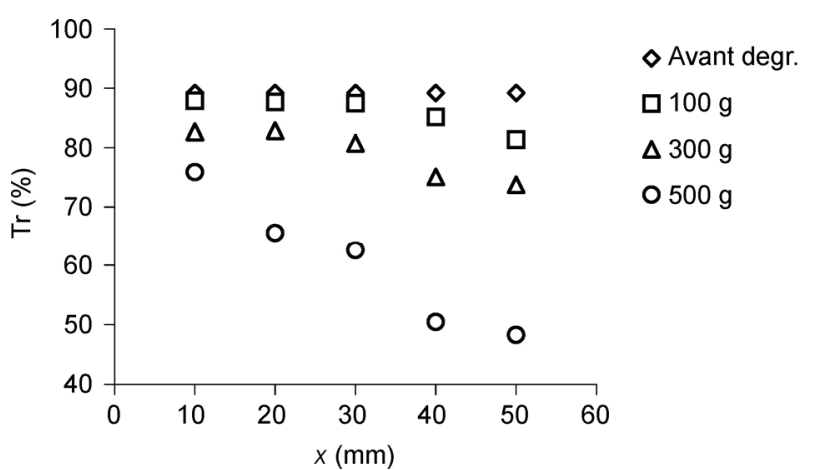

Fig. 7 Optical transmission at distance $\mathrm{x}$ from the point impact of soda-lime glass damaged by sandblasting for different sand quantities an angle of inclination $\theta=60^{\circ}$.

decrease, $\delta \sigma_{\mathrm{rc}}$ relative to the undamaged state, and the number of shocks, $N_{\mathrm{sr}}$, are summarized in Table 3.

\subsubsection{Biaxial bending measurements with circular supports}

The results of the mechanical strength measured by biaxial bending, $\sigma_{\mathrm{rf}}$ and the corresponding percentage decrease, $\delta \sigma_{\mathrm{rc}}$ relative to the undamaged state are summarized in Table 4.

\section{Discussion}

\subsection{Statistical interpretation}

The tests carried out showed that the three roughness measures $\left(R_{\mathrm{a}}, R_{\mathrm{q}}\right.$, and $\left.R_{\max }\right)$ do not exhibit the usual trend for the angle of inclination of $30^{\circ}$, whereas for the other two angles $\left(45^{\circ}\right.$ and $\left.60^{\circ}\right)$ the three measures of the roughness approach the normal distribution significantly for the damaged states $(100 \mathrm{~g}, 300 \mathrm{~g}, 500 \mathrm{~g})$,

Table 3 Mechanical strength (by shock ball) of the soda-lime glass damaged by sandblasting.

\begin{tabular}{ccccccccccc}
\hline \multirow{2}{*}{$M(\mathrm{~g})$} & \multicolumn{3}{c}{$\theta=30^{\circ}$} & \multicolumn{3}{c}{$\theta=45^{\circ}$} & \multicolumn{3}{c}{$\theta=60^{\circ}$} \\
\cline { 2 - 9 } & $\sigma_{\mathrm{rc}}(\mathrm{MPa})$ & $\delta \sigma_{\mathrm{rc}}(\%)$ & $N_{\text {sr }}$ & $\sigma_{\mathrm{rc}}(\mathrm{MPa})$ & $\delta \sigma_{\mathrm{rc}}(\%)$ & $N_{\text {sr }}$ & $\sigma_{\text {rc }}(\mathrm{MPa})$ & $\delta \sigma_{\text {rc }}(\%)$ & $N_{\text {sr }}$ \\
\hline 100 & $93.85 \pm 5.06$ & 1.5 & 7 & $92.69 \pm 6.44$ & 2.6 & 7 & $92.61 \pm 7.39$ & 2.7 & 7 \\
300 & $93.66 \pm 7.12$ & 1.6 & 7 & $91.13 \pm 8.42$ & 4.3 & 6 & $90.38 \pm 5.95$ & 5.1 & 6 & 8.1 \\
500 & $91.95 \pm 5.64$ & 3.4 & 6 & $87.50 \pm 8.21$ & 8.1 & 4 & $86.84 \pm 4.43$ & 8.8 \\
\hline
\end{tabular}

Table 4 Mechanical strength (by biaxial bending) of the soda-lime glass damaged by sandblasting.

\begin{tabular}{ccccccc}
\hline \multirow{2}{*}{$M(\mathrm{~g})$} & \multicolumn{2}{c}{$\theta=30^{\circ}$} & \multicolumn{2}{c}{$\theta=45^{\circ}$} & \multicolumn{2}{c}{$\theta=60^{\circ}$} \\
\cline { 2 - 7 } & $\sigma_{\mathrm{rf}}(\mathrm{MPa})$ & $\delta \sigma_{\mathrm{rf}}(\%)$ & $\sigma_{\mathrm{rf}}(\mathrm{MPa})$ & $\delta \sigma_{\mathrm{rf}}(\%)$ & $\sigma_{\mathrm{rf}}(\mathrm{MPa})$ & $\delta \sigma_{\mathrm{rf}}(\%)$ \\
\hline 100 & $66.10 \pm 7.85$ & 6.1 & $63.93 \pm 6.89$ & 9.2 & $62.91 \pm 5.72$ & 10.6 \\
300 & $58.33 \pm 4.25$ & 17.1 & $53.88 \pm 4.13$ & 23.5 & $51.31 \pm 3.28$ & 27.1 \\
500 & $48.28 \pm 3.33$ & 33.4 & $44.54 \pm 2.71$ & 36.7 & $42.03 \pm 2.72$ & 40.3 \\
\hline
\end{tabular}


but they do not show the tendency generally.

For optical transmission, the tests showed that it does not show the normal distribution for different sand quantities and different angles of inclination; thus the mechanical strength was determined by the two types of testing (shock ball and biaxial bending).

\subsection{Effect of the sand quantity}

For the undamaged state, we observed that the roughness measures $\left(R_{\mathrm{a}}, R_{\mathrm{q}}\right.$, and $\left.R_{\max }\right)$ are almost constant throughout the surface; compared with those of the damaged samples, they gradually increase with the sand quantity.

To characterize the effect of different sand quantities ( $100 \mathrm{~g}, 300 \mathrm{~g}, 500 \mathrm{~g}$ ) on the damage to the surface state, one compares the graphical representations in Figs. 2, 3 , and 4 .

The damages to the surfaces caused by the three quantities of sand resulted in surface structures that are almost similar to those of the undamaged state from the edge $(x=10 \mathrm{~mm})$ up to the point $x=20 \mathrm{~mm}$, and after this point (toward the center) the difference begins to appear distinct at $x=50 \mathrm{~mm}$; this can be explained by the the concentration of the sand grains which impacting in the middle of the specimen surface, caused by a guidance of the grains in the glass tube (see 10 of the device represented in Fig. 1).

From the graphs of the optical transmission (Tr) presented in the Figs. 5, 6, and 7, we notice that the optical transmission decreased as the quantity of sand was increased; this can be explained by the fact that while increasing the quantity of sand, the number of craters created on the surface by the grain bombardment increased, hence the decrease in the transmittance. That is, the decrease in the optical transmission is due to losses of light at the flans of the craters and microcracks (in our case, these are represented by $R_{\mathrm{q}}$ ), which means that while increasing the craters and microcracks, the transmission losses increase as well.

From the graphs of the rupture strength $\left(\sigma_{\mathrm{rc}}\right.$ or $\left.\sigma_{\mathrm{rf}}\right)$ in Tables 3 and 4, we notice clearly that the strengths of the damaged samples decrease as the quantity of sand is increased, which can be explained by the fact that while increasing the quantity of sand, the number of the longest microcracks (which in our case are represented by $R_{\max }$ ) created on the surface by the bombardment of the grains increases and thus the reduction of the mechanical strength.

From the Table 3, we observe that the relative variation of the mechanical strength by the shock ball, $\delta \sigma_{\mathrm{rc}}$ increases and the number of repeated shocks, $N_{\text {sr }}$ decreases while the quantity of sand for each inclination angle of the sample is increased.

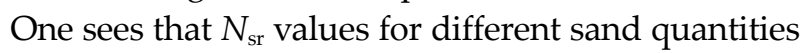
and angles of inclination are less than 10, which confirms that we are not in the hardness level $\left(N_{\mathrm{sr}} \geqslant 10\right)$ [8].

From Table 4, one notices that the relative variation of the mechanical strength by biaxial bending with circular rings, $\delta \sigma_{\mathrm{rf}}$, increases with increase in the sand quantity.

Also, one sees that the standard deviation of strength, $\sigma_{\mathrm{rf}}$ decreases while the sand quantity is increased, which can be explained by the convergence of $\sigma_{\mathrm{rf}}$ to a residual value corresponding to the greater quantity of the sand.

\subsection{Effect of the inclination of the surface}

The graphs of the measured roughness in Figs. 2, 3, and 4 show that the damage to the surface state increases with increase in the angle of inclination. This means that during the bombardment of the surface of the sample by a grain of sand, the impact energy is divided into a reduced sliding (grain rebounding) and an increase in energy scratching (absorbed by the surface which induces the craters and microcracks) while the angle of inclination is increased.

Figures 5, 6, and 7 show that the optical transmission decreases with the increase in the sample inclination. This is explained by the fact that scratching has the ability to create more craters and microcracks as sliding.

Tables 3 and 4, respectively, show that the mechanical strengths by the shock ball, $\sigma_{\mathrm{rc}}$ and by biaxial bending with circular supports, $\sigma_{\mathrm{rf}}$, decrease with increase in the inclination angles, which confirms the argument that the scratching has the tendency to create more craters and microcracks than sliding.

\subsection{Comparison between the two types of tests}

To better compare the results of both mechanical tests, we determined the relationship between the mechanical strength measured by the shock ball and that measured by biaxial bending $\left(\sigma_{\mathrm{rc}} / \sigma_{\mathrm{rf}}\right)$ for different quantities of sand and inclination angles. The calculated ratios are summarized in Table 5. 
Table 5 Ratio of the mechanical strength determined by the shock ball method to the values measured by biaxial bending.

\begin{tabular}{cccc}
\hline \multirow{2}{*}{$M(\mathrm{~g})$} & \multicolumn{3}{c}{$\sigma_{\mathrm{rc}} / \sigma_{\mathrm{rf}}$} \\
\cline { 2 - 4 } & $\theta=30^{\circ}$ & $\theta=45^{\circ}$ & $\theta=60^{\circ}$ \\
\hline 100 & 1.42 & 1.45 & 1.47 \\
300 & 1.60 & 1.69 & 1.76 \\
500 & 1.90 & 1.96 & 2.06 \\
\hline
\end{tabular}

From our experimental results of the mechanical strength by the shock ball method and biaxial bending that are given in Tables 3, 4, and 5, we note that:

$\checkmark$ The ratio of the mechanical strength measured by the shock ball to the corresponding values measured by biaxial bending is 1.35 for the undamaged state, but for the damaged state the ratio varies between 1.42 and 2; which is in agreement with that found by NOVOTNY [9-13] as:

$\frac{\sigma_{\mathrm{rc}}}{\sigma_{\mathrm{rf}}}= \begin{cases}1.48 & \text { For a flat glass before damage; } \\ 1.86 & \text { For the same glass after damage. }\end{cases}$

$\checkmark$ The mechanical strength measured by biaxial bending is smaller compared to that determined by the shock ball.

This observation can be explained in two ways:

- The absence of the fatigue phenomenon for the shock-ball test, since the load is instantaneous and yet the manifestation of fatigue for a bending test due to charging time is approximately $10 \mathrm{~s}$.

- The surface under the loads is greater for the biaxial-bending test than for the shock-ball test in which it is immediate, whereby it has a higher probability to develop critical microcracks which cause rupture.

\section{Conclusion}

The work we did consists in determining the damage effect caused by a deterioration of the mechanical strength of soda-lime glass by sand gravitation.

On the basis of the experimental results obtained, we conclude that:

- The roughness of the surface $\left(R_{\mathrm{a}}, R_{\mathrm{q}}\right.$, and $\left.R_{\max }\right)$, the optical transmission ( $\mathrm{Tr})$, and the mechanical strength $\left(\sigma_{\mathrm{rc}}\right.$ and $\left.\sigma_{\mathrm{rf}}\right)$ do not show expected behavior.

- The damage to the surface state increases with the increase in the sand quantity, and thus a reduction of the optical transmission and mechanical strength.

- The decrease in the optical transmission $(\Delta \operatorname{Tr})$ varies between $1.2 \%$ and $45.9 \%$ for increasing the quantities of sand and the inclination angles of the sample.

- The relative variation of the mechanical strength measured by the shock ball, $\delta \sigma_{\mathrm{rc}}$ varies between $1.5 \%$ and $8.8 \%$, but the one measured by biaxial bending, $\delta \sigma_{\mathrm{rf}}$, varies between $6.1 \%$ and $40 \%$ for increasing sand quantities and inclination angles.

- The number of repeated shocks, $N_{\mathrm{sr}}$ decreases with increase in the sand quantity for the shock balls.

- The deviation in the mechanical strength measured by biaxial bending, $\sigma_{\mathrm{rf}}$, decreases with increase in the sand quantity and inclination angle.

- The damage to the surface state increases for increasing inclination angles, and hence a reduction in the mechanical strength.

- The mechanical strength obtained by biaxial bending is smaller than the one determined by the shock ball measurement, and the ratio of the mechanical strength measured by the shock ball to the value by biaxial bending is 1.35 for the state before degradation, but it varies from 1.42 until 2 for the damaged state while the sand quantity and inclination angle are increased.

Therefore, by the results of this study, we have obtained information that could be useful and very important for a good understanding of the influence of damage by sandblasting on the mechanical strength of soda-lime glass.

Open Access: This article is distributed under the terms of the Creative Commons Attribution License which permits any use, distribution, and reproduction in any medium, provided the original author(s) and source are credited.

\section{References}

[1] Zarzycki J. In Le verre et l'état vitreux. Paris: Edition Masson, 1982: 300-324.

[2] Uhlmann D R, Kreidel N. Glass Science and Technology Elasticity and Strength in Glass. London: Edition Academic Press, 1980: 21-75. 
[3] Scholtze H. In Le verre (Nature, Structure et Propriétés). Paris: Edition Institut de Verre, 1980: 218-238.

[4] Mould R E, Southwick R D. Strength and static fatigue of abraded glass under controlled ambient conditions. J Am Cer Soc 42: 542-547 (1959)

[5] Ludwig M A, Stoner R B. Quantitative abrasion resistance of optical coating and surfaces. J Appl Phys 60: 4277 (1986)

[6] Benbahouche S, Roumili F, Seghir A, Zegadi R. Mechanical strength of soda-lime glass damaged by sand graviatation. In $6^{\text {th }}$ Conference European Science of Glass, Montpellier, France, 2002: 174.

[7] Benbahouche S, Roumili F, Zegadi R. Mechanical strength of tempered soda-lime glass damaged by sand graviatation, determined by bending with circular supports. Glass Technol 43C: 286-289 (2002)

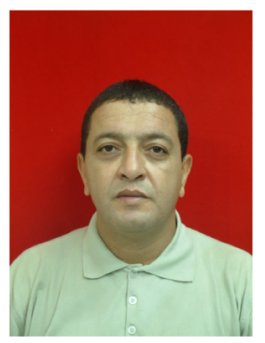

Saci BENBAHOUCHE. He is a professor since 2011, at Optics and Precision Mechanical Institute, Ferhat Abbas University, Setif Algeria. He obtained his $\mathrm{PhD}$ degree in optics and precision engineering at

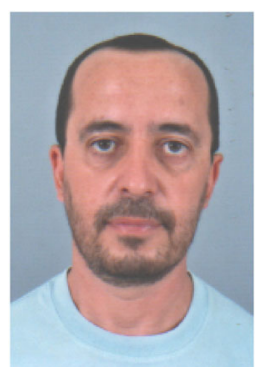

Fouad ROUMILI. He is an assistant professor, at Optics and Precision Mechanical Institute, Ferhat Abbas University, Setif Algeria. He obtained his $\mathrm{PhD}$ degree in Physics from

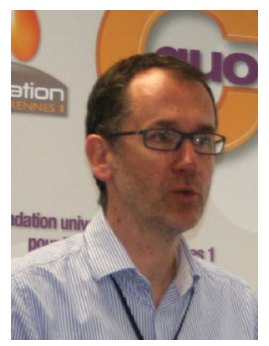

Jean-Christophe SANGLEBOEUF. $\mathrm{He}$ is a professor and head of the Department of Mechanics and Glasses, Université de Rennes,
[8] Sadi A. Influence de l'état de surface sur la résistance mécanique du verre. In Thèse de Magister, IOMP, U.F.A. Sétif, Algerie, 1987: 45-47.

[9] Novotny, Vich, Kubista. Résistance en flexion et au choc de quelques verres industriels. Silikaty 22: 329-346 (1978)

[10] Manuel pour la fabrication du verre. Moscou, U.R.S.S, 1963: 5705-5729.

[11] Reports by the technical committee of the society glass technology, 1969.

[12] Standard methods of flexure testing of glass. A.S.T.M.C., 1982: 103-112.

[13] Benbahouche S, Roumili F, Aliouane A, Sangleboeuf J-C. Mechanical strength of glass ground by various fractions. Eur J Glass Sci Technol A 51(5): 202-204 (2010)

the Optics and Precision Mechanical Institute, Ferhat Abbas University in 2005. His research focuses on the mechanical and optical characterization of brittle materials especially glasses, and simulation and modeling.

University Louis Pasteur Strasbourg I, France in 1992. His research focuses on the mechanical and optical characterization of brittle materials especially glasses.

Institut de Physique de Rennes (IPR). His research focuses on mechanical and micromechanics behavior of materials, nanomechanics, and glass science and technology. 